\title{
An infant who suffered seizures many times after pentavalent vaccination: A case report
}

\author{
Meryem Erat Nergiz, ${ }^{1}$ 을 Hande Yetisgin, ${ }^{1}$ () Alperen Aydin, ${ }^{1}$ () Gulsum Iclal Bayhan, ${ }^{2}$ \\ D Aysegul Nese Citak Kurt ${ }^{3}$ \\ ${ }^{1}$ Department of Pediatrics, Ankara Yildirim Beyazit University, Yenimahalle Training and Research Hospital, Ankara, Turkey \\ 2Department of Pediatric Infectious Diseases, Ankara Yildirim Beyazit University, Yenimahalle Training and Research Hospital, Ankara, Turkey \\ ${ }^{3}$ Department of Pediatric Neurology, Ankara Yildirim Beyazit University, Yenimahalle Training and Research Hospital, Ankara, Turkey
}

\begin{abstract}
Although rare, serious adverse effects may be seen after vaccination. Especially, the whole-cell pertussis vaccine has been held responsible for neurological side effects, as the most important problem in vaccination. With the advancement in vaccination technologies, whole-cell pertussis vaccine has been replaced by acellular pertussis vaccine, and neurological side effects have been significantly reduced. Herein, we present a 2-month-old male infant who suffered from generalized tonic-clonic seizures many times, possibly due to acellular pertussis after pentavalent vaccination, including diphtheria, acellular pertussis, tetanus, inactive polio, Haemophilus influenzae type B, and conjugate pneumococcal vaccine (BCG, DaBT-IPA-Hib, CPV).

Keywords: Infant; seizure; pentavalent vaccination.
\end{abstract}

Cite this article as: Erat Nergiz M, Yetisgin H, Aydin A, Bayhan GI, Citak Kurt AN. An infant who suffered seizures many times after pentavalent vaccination: A case report. North Clin Istanb 2020;7(3):302-304.

$V^{2}$ accination prevents many infectious diseases and millions of mortality and disabilities worldwide. Although extremely rare, vaccines may have serious adverse effects. Especially, neurologic side effects, such as convulsion, hypotonic-unresponsive seizures syndrome, persistent crying, and encephalopathy, have been common in whole-cell pertussis vaccine, and this was the most important problem in vaccination. Therefore, many countries have switched to acellular pertussis vaccine, which has less serious neurologic side effects instead of whole-cell pertussis vaccine [1]. In Turkey also, the pertussis vaccine has been involved in the pentavalent vaccination as acellular since 2008. In this case report, we present a 2 -month-old male infant with repetitive convulsion episodes following pentavalent vaccination.

\section{CASE REPORT}

A 2-month-old male infant was referred to the emergency pediatric outpatient clinic of our hospital with complaints of extremity contractions and severe crying. His medical history revealed that he was born in term from the first pregnancy of the mother with a cesarean because of non-progressing labour with a birth weight of 3100 gr, no perinatal and postnatal complications were developed, and the infant did not require resuscitation or neonatal intensive care. The patient did not suffer any disease thereafter. No history of epilepsy was found in the family members. It was learned that the patient had been immunized with the pentavalent vaccine (BCG, DaBT-IPA-Hib, CPV) at two months-age old at Family

54. Turkish Pediatric Congress (poster), 6-10 May 2018 / KKTC

Received: September 29, 2018 Accepted: May 08, 2019 Online: April 09, 2020

Correspondence: Dr. Meryem ERAT NERGIZ. Ankara Yildirim Beyazit Universitesi, Yenimahalle Egitim ve Arastırma Hastanesi, Cocuk Sagligi ve Hastaliklari Anabilim Dali, Batikent, Yenimahalle, Ankara, Turkey.

Tel: +90 3125872000 e-mail: meryemerat@hotmail.com

(c) Copyright 2020 by Istanbul Provincial Directorate of Health - Available online at www.northclinist.com 
Health Center, severe crying and contractions in the extremities started one hour after the vaccination. The contractions lasted 4-5 seconds, and he suffered episodes of contractions in both lower and upper extremities with crying. The seizures repeated about 10 times and the patient had no fever.

In the physical examination, the heart rate was 116 $/ \mathrm{min}$, blood pressure was $80 / 50 \mathrm{mmHg}$, body temperature was $36.8^{\circ} \mathrm{C}$, he was conscious, muscle tone was normal, anterior fontanelle was open and with normal bulging, and no pulsation was observed. The other physical examination findings were normal. The patient suffered from a short generalized tonic-clonic seizure during the examination. In the laboratory investigations, white blood cell count was $15.700 / \mathrm{mm}^{3}$, hemoglobin $10.1 \mathrm{~g} / \mathrm{dL}$, platelet $444000 / \mathrm{mm}^{3}$, C reactive protein $0.01 \mathrm{mg} / \mathrm{dL}$, and the biochemical parameters were normal. No any intracranial pathology was found on transfontanelle ultrasonography. The electroencephalogram (EEG) was ordered and the patient suffered from an active generalized a tonic-clonic seizure during the EEG recording. EEG revealed a mildly active epileptic disorder arose from the central region. The patient was administered phenobarbital loading therapy, with the subsequent maintenance dose. The patient who had no fever and seizures was discharged with a prescription of phenobarbital maintenance therapy. This case reported to the vaccine adverse effects reporting system of the Ministry of Health. Seizures following vaccination are not a contraindication for the next vaccine. He was hospitalized at the 4-moths-age for DaBT-IPA-Hib, CPV vaccination. No side effect was seen 24 hours after the vaccination and the patient was discharged. The vaccine (DaBT-IPA-Hib, CPV) was repeated at six monthsage of the again in the hospital setting. The patient was monitored for six hours and no any side effect occurred. Developmental steps are normal during the follow-up, and the patient is currently under phenobarbital therapy. Signed consent was obtained from the parents for this publication.

\section{DISCUSSION}

The most important problem in pertussis vaccination was the neurologic side effects, such as convulsion and encephalopathy, which are related with the whole-cell pertussis vaccine. With switching to acellular pertussis vaccine, these adverse effects have been significantly reduced $[1,2]$. Side effects of whole-cell pertussis vaccine are significantly higher than those of acellular vaccine because acellular pertussis vaccine contains $2-5$ proteins, while the whole-cell vaccine contains approximately 3000 proteins, and again the whole-cell vaccine contains endotoxin which is known as a neurotoxin, pertussis toxin, and adenylate cyclase [2]. The wholecell pertussis vaccine has been replaced with acellular pertussis vaccine in many regions of the world because of its neurologic side effects. In our country also, the acellular pertussis vaccine has been introduced since 2008. According to our current national vaccination calendar, diphtheria, pertussis, tetanus, inactive polio and Haemophilus influenzae type B (DaBT-IPA-Hib) $\left(\right.$ Pentaxim ${ }^{\mathrm{R}}$ ) are made as three doses at the ends of the $2^{\text {nd }}, 4^{\text {th }}$ and $6^{\text {th }}$ months of life, and booster vaccination is administered at the $18^{\text {th }}$ month (DaBT-IPA-Hib), and in the first year of primary school (DaBT-IPA). According to data from the World Health Organization (WHO), persistent crying is seen by $3.5 \%$ after the whole-cell pertussis vaccine, while this rate is $0-0.2 \%$ after the acellular vaccine. Hypotonic-unresponsive seizures syndrome is seen by $57-25$ per 100.000 after whole-cell vaccine and 14-62 per 100.000 after acellular vaccine. Convulsion is seen by six per 100.000 in the whole-cell vaccine and 0.5 per 100.000 in the acellular vaccine. There is a known risk of the acellular vaccine for encephalopathy, while this risk is $1.3 / 1000.000$ in the whole-cell vaccine.

Rates of side effects, such as seizures, encephalitis, encephalopathy and altered mental status, which are seen after DaBT-IPA-Hib, have been found similar compared with the other vaccines containing $\mathrm{DaBT}$, and no increased risk has been found in the other component of the vaccine $[3,4]$.

There are many studies demonstrating that the DaBT vaccine is safe for neurologic side effects [5-7]. In a comprehensive study, Huang WT et al. [6] retrospectively evaluated 433.654 infants aged between six weeks and 23 months and found no statistically significant increase in the risk for suffering convulsions within the first three days after DaBT-IPA-Hib vaccination.

In another study, infants were evaluated for the risk of convulsions after DaBT-IPA-Hib vaccines made at $3^{\text {rd }}$, $5^{\text {th }}$, and $12^{\text {th }}$ months, and the authors showed a significantly increase in the risk of suffering febrile convulsion in the first two days after the vaccination at the $3^{\text {rd }}$ and $5^{\text {th }}$ months, but they found no increased risk of epilepsy after vaccination [8]. To our knowledge, there is not 
any study in the literature reporting afebrile repetitive seizures after 5 -in- 1 combination vaccine.

Seizures may be a possible side effect of vaccine, but it may also be the first manifestation of an epileptic disorder induced by vaccination. Berkovic et al. [9] studied 14 patients who had their first seizure within the first 72 hours after vaccination, and who were then followed-up with the diagnosis of resistance epilepsy, and they found a mutation in SCN1A encoding alpha 1 lower unit of the sodium canal. The authors concluded that encephalopathy-resistant convulsion might actually be associated with genetic epileptic syndromes, and this would positively affect the adoption of the vaccines by society if this could be confirmed with further studies.

Contraindications of the vaccines should be wellknown. The only definite contraindication for all vaccines is previous anaphylaxis experienced with vaccines. Suffering seizure after the DaBT vaccine is not a contraindication for the next vaccination [10]. We also continued vaccines of the patient in compliance with the vaccination calendar and did not observe any complication during follow-up.

In conclusion, although the acellular pertussis vaccine is safer than the cellular vaccine, it may rarely lead to adverse effects. However, given morbidity and mortality that arise from a pertussis infection, these effects are extremely rare. Thus, they do not cause a debate on the safety of this vaccination. Suffering seizures following vaccination is not a contraindication for the next vaccine, and vaccination should be maintained under suitable conditions.

Informed Consent: Written informed consent was obtained from the patient for the publication of the case report.

Conflict of Interest: No conflict of interest was declared by the authors.

Financial Disclosure: The authors declared that this study has received no financial support.
Authorship Contributions: Concept - MEN, ANCK; Design - MEN, GIB; Supervision - AA, HY; Fundings - AA, HY; Materials - GIB, ANCK; Data collection and/or processing - HY, AA; Analysis and/or interpretation - MEN, ANCK; Literature review - MEN, HY; Writing MEN; Critical review - MEN.

\section{REFERENCES}

1. Korkmaz HA, Aydin A, Unal B. Comparison of acellular pertussis-tetanus-diphtheria vaccines and whole-cell pertussis-tetanus-diphtheria vaccines in infancy. Paediatr Int Child Health 2014;34:198-202.

2. Geier DA, Geier MR. An evaluation of serious neurological disorders following immunization: a comparison of whole-cell pertussis and acellular pertussis vaccines. Brain Dev 2004;26:296-300. [CrossRef]

3. Hansen J, Timbol J, Lewis N, Pool V, Decker MD, Greenberg DP, et al. Safety of DTaP-IPV/Hib vaccine administered routinely to infants and toddlers. Vaccine 2016;34:4172-9. [CrossRef]

4. Nelson JC, Yu O, Dominguez-Islas CP, Cook AJ, Peterson D, Greene SK, et al. Adapting group sequential methods to observational postlicensure vaccine safety surveillance: results of a pentavalent combination DTaP-IPV-Hib vaccine safety study. Am J Epidemiol 2013;177:13141. [CrossRef]

5. Braun MM, Mootrey GT, Salive ME, Chen RT, Ellenberg SS. Infant immunization with acellular pertussis vaccines in the United States: assessment of the first two years' data from the Vaccine Adverse Event Reporting System (VAERS). Pediatrics. 2000;106(4):E51. [CrossRef]

6. Huang WT, Gargiullo PM, Broder KR, Weintraub ES, Iskander JK, Klein NP, et al. Lack of association between acellular pertussis vaccine and seizures in early childhood. Pediatrics 2010;126:263-9. [CrossRef]

7. Zangwill KM, Eriksen E, Lee M, Lee J, Marcy SM, Friedland LR, et al. A population-based, postlicensure evaluation of the safety of a combination diphtheria, tetanus, acellular pertussis, hepatitis B, and inactivated poliovirus vaccine in a large managed care organization. Pediatrics 2008;122:e1179-85. [CrossRef]

8. Sun Y, Christensen J, Hviid A, Li J, Vedsted P, Olsen J, Vestergaard M. Risk of febrile seizures and epilepsy after vaccination with diphtheria, tetanus, acellular pertussis, inactivated poliovirus, and Haemophilus influenzae type B. JAMA 2012;307:823-31. [CrossRef]

9. Berkovic SF, Harkin L, McMahon JM, Pelekanos JT, Zuberi SM, Wirrell EC, et al. De-novo mutations of the sodium channel gene SCN1A in alleged vaccine encephalopathy: a retrospective study. Lancet Neurol 2006;5:488-92. [CrossRef]

10. Opri R, Zanoni G, Caffarelli C, Bottau P, Caimmi S, Crisafulli G, et al. True and false contraindications to vaccines. Allergol Immunopathol (Madr) 2018;46:99-104. [CrossRef] 